REVISTA CIENCIAS BIOMÉDICAS

EN PORTADA

2016; 7(1): 15-17

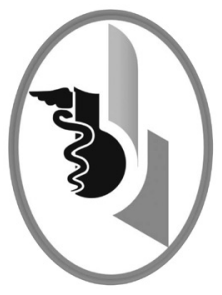

\title{
CARLOS BAUTISTA CRUZ ECHEVERRÍA
}

El profesor Carlos Bautista Cruz Echeverría nació el 29 de agosto de 1927 en un hogar humilde en la ciudad de Barranquilla. Antes que tuviese un año de edad, sus padres se trasladaron a la ciudad de Cartagena, también en el Caribe colombiano, donde permaneció toda su vida. Realizó estudios de Medicina en la Facultad de Medicina de la Universidad de Cartagena, donde se graduó y obtuvo el título de Médico en la promoción de 1956. Realizó la tesis: "Peritoneoscopia aplicada al diagnóstico de las vías biliares". Fue becado por el Ministerio de Salud y por un par de meses fue a Venezuela a realizar estudios de Malariología.

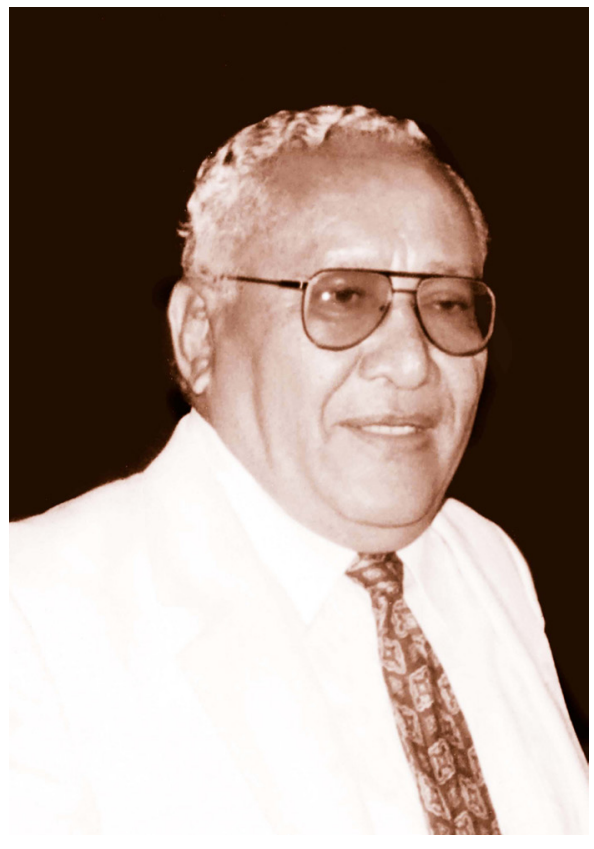

Previamente, entre los años de 1952 y 1957, siendo estudiante de Medicina, fue disector y jefe de Trabajos Prácticos del Departamento de Morfología de la misma universidad. Prestó el servicio de internado en el Hospital Santa Clara por doce meses de 1954 y 1955.

Posteriormente, partió a México, donde en el Instituto Nacional de Neurología en el D.F. realizó estudios en Neurología Clínica. A su regreso en 1959, se vinculó a la Facultad de Medicina de la Universidad de Cartagena siendo nombrado Jefe de Trabajos Prácticos en el Departamento de Morfología e inició una importante actividad como docente, la cual desempeñó por más de 20 años hasta alcanzar la condición de jubilación.

Desde su ingreso fue asignado al Departamento de Anatomía, por muchos años fue el encargado de la cátedra de Neuroanatomía. Era diestro en el dibujo anatómico y con su habilidad asombraba a estudiantes y a otros docentes. Dibujaba con tizas de colores en el tablero las diferentes vías nerviosas, piramidales y extrapiramidales con las cuales explicaba el funcionamiento e interconexión de las señales eléctricas dentro del sistema nervioso central y su comunicación con el sistema nervioso periférico, y el entorno del individuo. 
Completaba sus clases teóricas con explicaciones minuciosas sobre modelos anatómicos reales, detallaba los diferentes núcleos, sustancias y áreas anatómicas correlacionándolos con las funciones que cumplía el sistema nervioso y con el establecimiento de algunas patologías. Con facilidad explicaba áreas que los estudiantes consideraban difíciles de comprender; con agilidad describía aspectos inherentes a la morfología y al funcionamiento de los pares craneales y la interrelación entre ellos.

La experticia en el conocimiento anatómico detallado permite catalogarlo como anatomista, puesto que retomó definiciones que incluso habían quedado en el pasado de la historia de la medicina. Teniendo en cuenta que el Dr. Cruz Echeverría se concentró en la anatomía del sistema nervioso, sería justo denominarlo neuroanatomista, siendo tal vez uno de los profesionales de dicha área que más descolló en el desarrollo de la Facultad de Medicina de la Universidad de Cartagena -especialmente en dicho espacio académico-.

El doctor Cruz Echeverría fue profesor de Histología, Embriología y Neurología Clínica. Fue profesor visitante de las Facultades de Medicina de Bucaramanga y del Valle en Colombia, asimismo de la Facultad de Medicina de la Universidad del Oriente en Ciudad de Bolívar-Venezuela.

Si bien Carlos Cruz Echeverría se sitúa en el final de la era anatomista, también estuvo en el instante en que surgieron escuelas a nivel latinoamericano, siguiendo vientos desde países desarrollados que buscaban consolidar el conocimiento neuronal bajo una nueva denominación con más amplio alcance: las ciencias neurológicas. Su aporte docente en Neuroanatomía y Neurofisiología encaja y marca también el nacimiento de las neurociencias en la Facultad de Medicina de la Universidad de Cartagena. Posteriormente, sobre las primeras piedras de Cruz Echeverría, otros profesionales llegarían y realizarían importantes aportes para la adecuada enseñanza, aprendizaje y asistencia médica de la neurología clínica, e incluso, para el accionar operatorio con la subsiguiente creación del Postgrado de Neurocirugía.

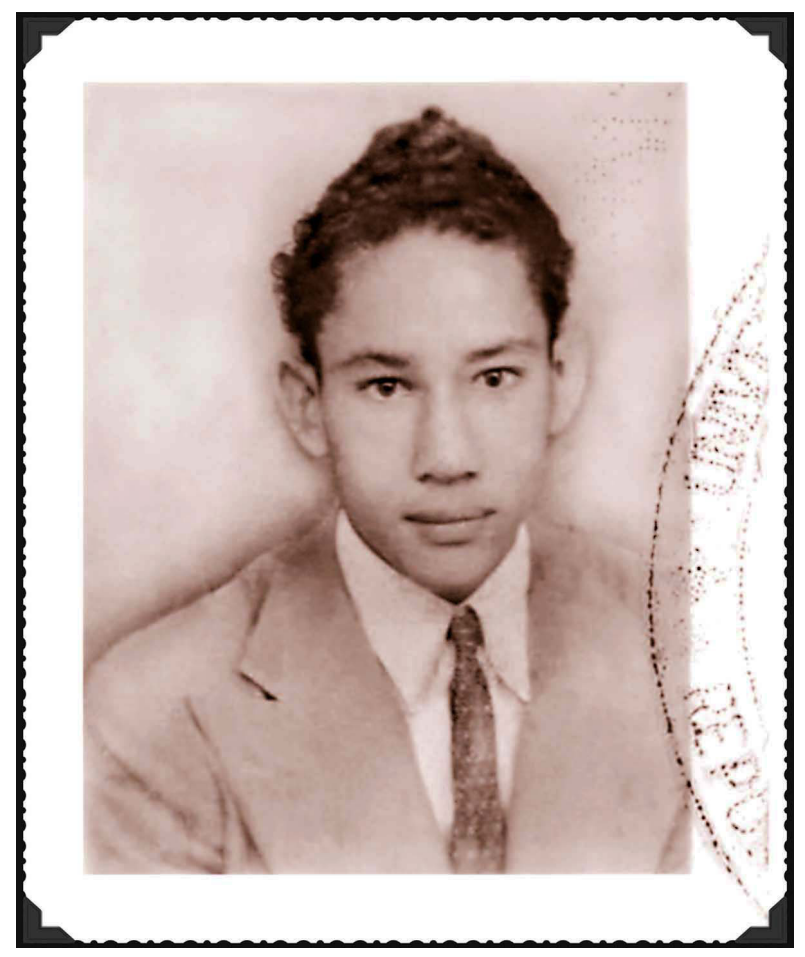

Facsímil de la fotografía presente en su carné estudiantil al ingresar a la Facultad de Medicina de la Universidad de Cartagena. 1948.

Carlos Cruz Echeverría fue un hombre de pensamiento diestro y coloreado de humor. No fue un científico puro, aislado del mundo y de sus problemas sociales, todo lo contrario, la sensibilidad social y humana lo llevó a moverse a la vanguardia del ámbito político y la dirigencia social. Fue concejal de la ciudad de Cartagena en varios períodos, dirigente deportivo local y nacional, realizó aportes desde el área médica en el campo del boxeo. Sus textos sobre la postura profesional médica para el cuidado y protección de los boxeadores se publicaron en diferentes medios, incluso en lengua inglesa. De forma temprana se acercó a lo que hoy se denomina medicina del deporte, tuvo una columna sobre medicina y deporte en un periódico de amplia circulación regional, desde ese espacio educó a los deportistas y a la comunidad en general sobre los aspectos saludables del deporte.

Escribió por varios años columnas de opinión en periódicos de la ciudad de Cartagena y en otros de circulación regional, donde abordó 
temas diversos y de interés ciudadano, siendo punzante en problemáticas sociales y políticas. No obstante, nunca perdió oportunidad para educar a la comunidad sobre aspectos referentes a la salud, especialmente sobre la salud mental. La Revista Ciencias Biomédicas presenta en su sección Las letras del maestro, Volumen 7(1):164-176, fragmentos de algunas de sus columnas para visibilizar su pensamiento médico y profesional.

Escribió dos relatos en el libro Pasiones de biches y maduros y una novela: Los asombros de Congobarato, donde combinó con maestría el sarcasmo y el humor, burlándose de la realidad social que le tocó vivir, inspirándose en amigos, detractores y en la realidad mágica del Caribe y sus actores. La Revista Ciencias Biomédicas presenta en su sección Historia de la Medicina de Cartagena, Volumen 7(1):157-163, una sinopsis de sus tres relatos de ficción.

Carlos Cruz Echeverría es uno de los médicos cartageneros que, por medio de la ficción, retrató con pasión su entorno Caribe. Como un hombre pacífico, de lento caminar, de bohemia moderada y gran conversador es aún recordado por muchos de sus alumnos, compañeros y amigos. Falleció en la ciudad de Cartagena el 13 de octubre del año 2002, a la edad de 75 años.

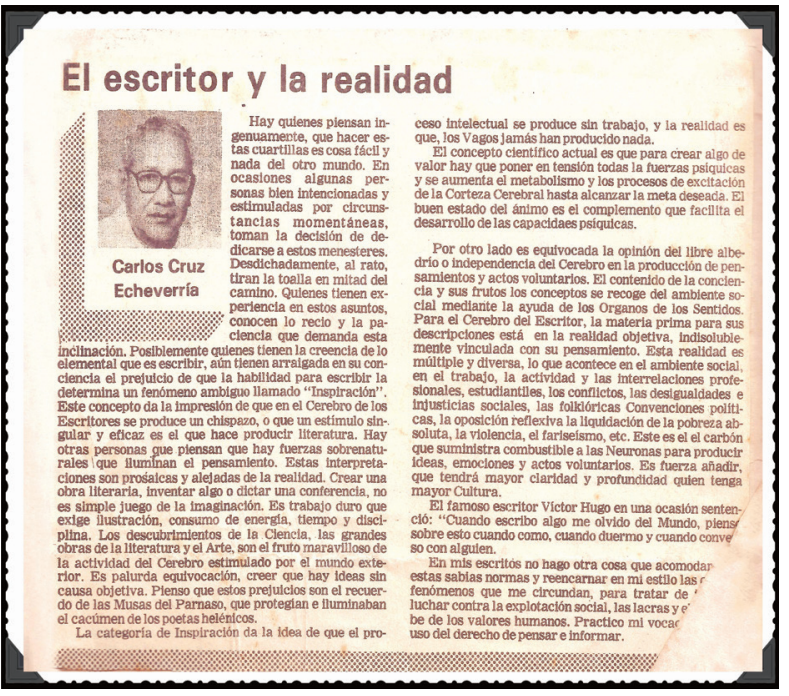

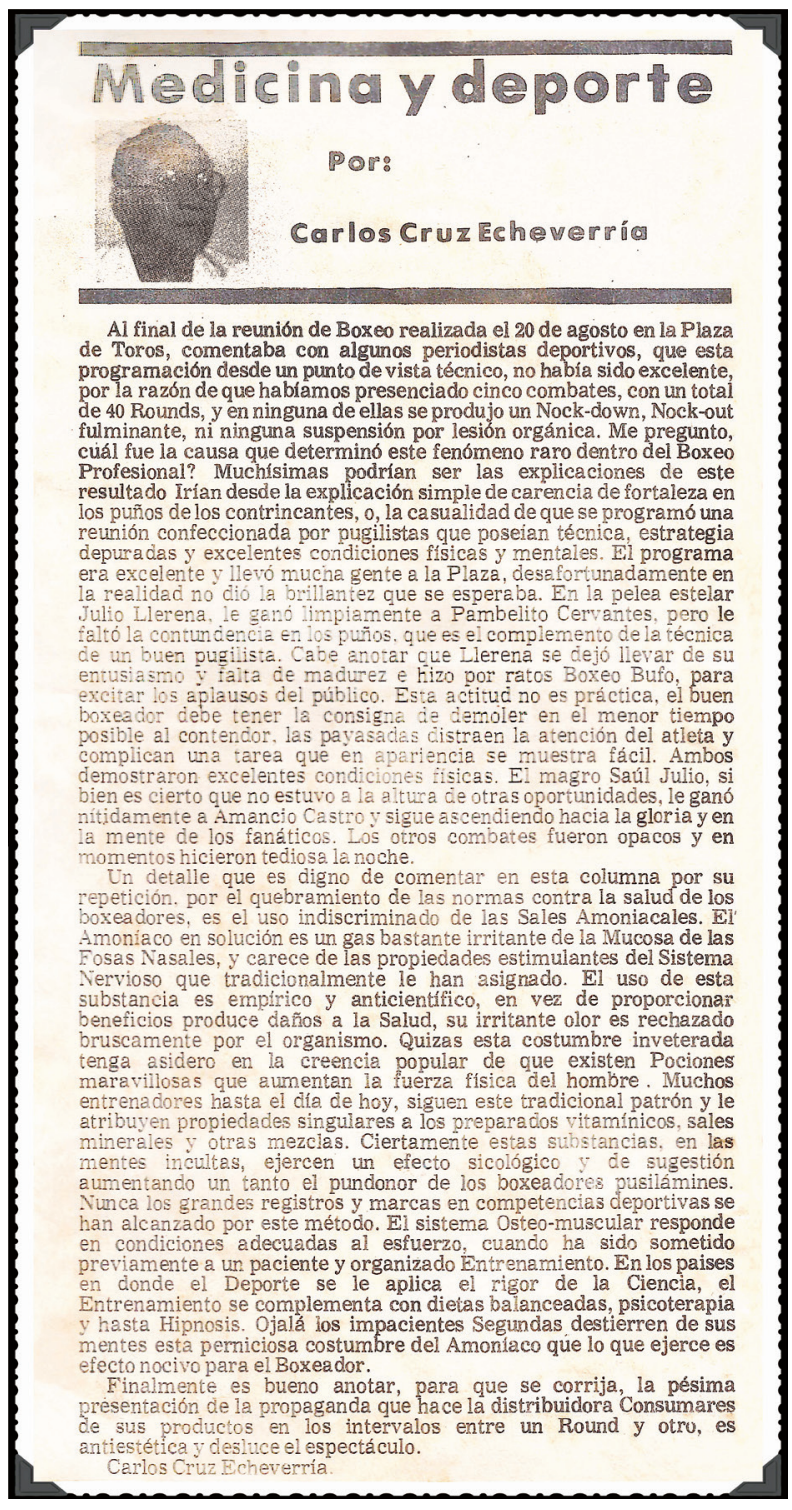

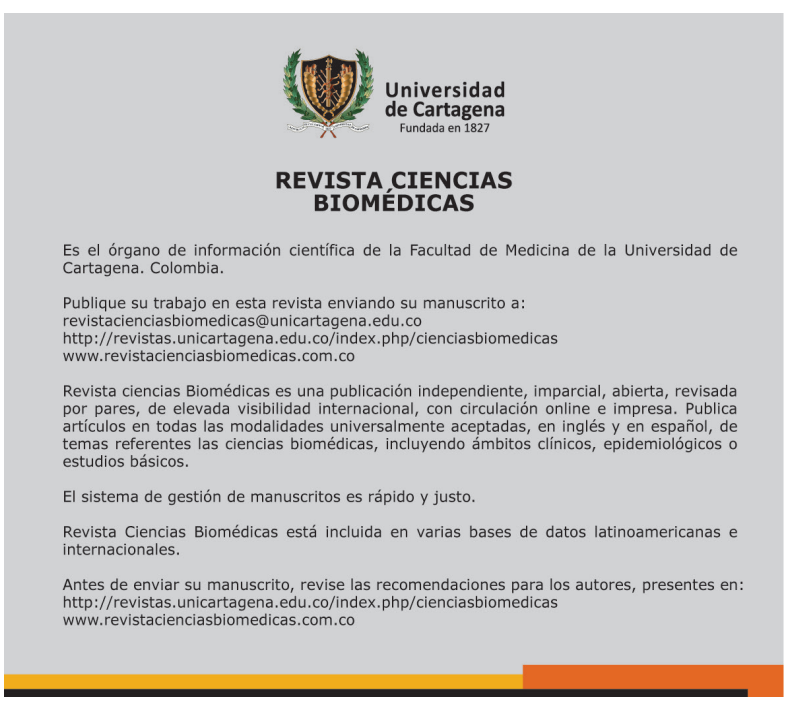

